\title{
Liraglutide Treatment Experience in Morbid Obese Adolescent with a MC4R Gene Variant: Side Effects Reduce Success
}

\section{Çamtosun $\mathrm{E}$ et al. Liraglutide treatment in a case of $M C 4 R$ defect}

Emine Çamtosun, Ayşehan Akıncı, Leman Kayaş, Nurdan Çiftçi, İbrahim Tekedereli İnönü University Faculty of Medicine, Department of Pediatric Endocrinology, Malatya

İnönü University Faculty of Medicine, Department of Medical Biology and Genetics, Malatya

\section{What is already known about this topic?}

Melanocortin-4 receptor (MC4R) defects cause monogenic obesity. In this situation management of obesity is challengin because of excessive appetite, it is unlikely to achieve weight loss over the long term with standard methods. Recently, Liraglutide treatment has been reported to provide weight loss in these patients with only gastrointestinal side effects.

\section{What this study adds?}

We presented a longer (43 weeks) experience of Liraglutide treatment in an adolescent patient carrying MC4R variant. We reported that, the drug could not be tolerated for a longer period of time due to gastrointestinal side effects, and discontinuation of treatment led to rapid weight gain.

\begin{abstract}
Variants of the melanocortin-4 receptor $(M C 4 R)$ gene are the most common cause of monogenic obesity. In this situation; while obesity cannot be controlled with diet and exercise, it was shown that Glucagon-like-peptide-1 receptor agonists (GLP1 RA) provide weight loss in short term. In this paper, we present our experience with Liraglutide treatment in an adolescent patient carrying MC4R gene variant. A female patient had admitted first at the age of 12.5 years with a complaint of progressive weight gain. She had a marked excess of appetite since infancy. In the physical examination of the pubertal female patient with a body mass index (BMI) of $36.1 \mathrm{~kg} / \mathrm{m} 2(3.48 \mathrm{SDS})$, there was no pathological finding except diffuse acanthosis nigricans. Laboratory examinations revealed oniy insulin resistance. Weight loss couldn't be achieved with lifestyle changes, metformin and orlistat treatments In genetic examination, a sporadic heterozygous c.206T $>\mathrm{G}(\mathrm{p} . \mathrm{I} 69 \mathrm{R})$ variant (reported previously) was found in the MC4R gene. GLP-1 RA Liraglutide treatment was initiated and a loss of $19.2 \%$ reduction was achieved in the patient's body weight and BMi at the end of 32 weeks. However, the patient, whose treatment compliance was disrupted due to significant gastrointestinal complaints, returned to her former weight within a few months after treatment was stopped. In our case carrying a pathogenic variant in the MC4R gene, decrease of appetite and weight loss were achieved with Liraglutide treatment, but this situation could not be maintained. In such cases, there is a need for effective and tolerable treatment option

Keywords: melanocortin 4 receptor defect, obesity, treatment, Liraglutide, side effect
\end{abstract}

Emine Çamtosun, Assistant Professor, MD, Department of Pediatric Endocrinology, İnonu University Faculty of Medicine, Malatya, Turkey

+90 4223410660 (5377)

epurcuklu@gmail.com

$0000-0002-8144-440^{\circ}$

25.05 .2021

24.09.2021

Published: 27 September 2021

INTRODUCTION

Variants of the melanocortin-4 receptor (MC4R) gene are the most common cause of non-syndromic monogenic obesity (1). The interaction of MC4R with alpha-melanin stimulating hormone causes a decrease in appetite and food intake. Pathogenic variants of the MC4R gene located in chromosome $18 \mathrm{q} 21.32$ cause early onset severe obesity. Dominant inherited obesity due to variants of the MC4R gene in humans was first described in 1998 (2). Today, more than 300 variants in the gene are known (3). The frequency of variants in the MC4R gene in individuals with early onset and severe obesity has been reported to be $5.7-8.6 \%(1,4,5)$. Early-onset severe obesity, tall stature, hyperphagia, increased lean body mass, normal pubertal age, and normal fertility have been reported in these individuals $(1,4)$. Hyperinsulinemia is a common finding of the disease, and no pathology has been found in other hormones. Farooqi et al. reported that 23 of 29 cases, whom they detected variants in the MC4R gene, carried heterozygous variants, while 6 carried homozygous variants, and the phenotype was more severe in cases carrying homozygous variants (1). Currently, no specific treatment method recommended for the management of obesity due to MC4R variants. Long-term success could not be achieved with lifestyle changes (diet, exercise, behavioral therapy) $(6,7)$. A study has been published showing that subcutaneous use of GLP-1 RA Liraglutide $3 \mathrm{mg} /$ day for 16 weeks reduces appetite in these cases and provides similar weight loss compared to the obese controls (8). This study reported only gastrointestinal side effects (nausea, vomiting, abdominal pain, diarrhea, constipation, reflux) which were generally mild and transient. Subcutaneous liraglutide was generally well tolerated in clinical trials among obese and overweight adults. Most of 
the side effects reported during treatment were gastrointestinal complaints. The most common causes of discontinuation of treatment were nausea, vomiting and diarrhea (9). In an another study, conducted on a small number of patients with heterozygous $M C 4 R$ variants, a weight loss, which was not different from placebo, was found after four weeks of treatment with the MC4R agonist Setmelanotide (Phase 1b study) (3). However, these two drugs have not yet been used in larger patient groups with MC4R variants, especially for long-term. In studies evaluating the efficacy of bariatric surgery in this patient group, the most frequently used method was gastric bypass and in most of these studies, similar weight loss was obtained compared to the obese patients without variants (10). However, long-term results are contradictory and there was lower success in some variations. In this report, we presented our experience with GLP-1 RA treatment in a morbid adolescent girl with a variant in the MC4R gene.

\section{CASE}

Female patient had admitted first at the age of 12.5-year-old with a complaint of excess weight. She was born $3000 \mathrm{~g}$ at term fed with breast milk until the age of three, supplementary food was added after six months of age, her motor-mental development was normal and she was obese since infancy. She was followed up for cyclic neutropenia and recurrent urinary tract infection, and had tonsillectomy and appendectomy operations. There was no history of serious obesity in the family On admission, her body weight (VA) was $89 \mathrm{~kg}$ (>97p), height was $157 \mathrm{~cm}(50-75 \mathrm{p})$, and body mass index (BMl) was 36.1 $\mathrm{kg} / \mathrm{m} 2(3.48 \mathrm{SD})$. There was no goiter in the physical examination, the pubertal stage was 3. Cervical and axillary acanthosis nigricans was observed in the patient. She looked obese with a diffuse body fat distribution. Her mental status was normal. There was no dysmorphic finding. Laboratory examinations revealed leukopenia and high fasting insulin level (Table 1). Hepatosteatosis was not detected in abdominal ultrasonography. The patient, who was recommended diet, exercise, Metformin 2x500 mg (oral) treatments, could not adapt to diet and exercise, and did not use Metformin regularly. In the OGTT performed at the age of 13.9 years, serum glucose and insulin levels at the 120th minute was $163 \mathrm{mg} / \mathrm{dl}$ and 244 $\mathrm{mcIU} / \mathrm{mL}$ respectively. Glycohemoglobin was $5.5 \%$ (4.5-6.5). When she was 17.2 years old her BMI was found to be 48 (4.5 SD). She had excessive appetite, could not keep on diet and did not use Metformin treatment regularly because of nausea and dizziness. She was recommended to use Orlistat $2 \times 120 \mathrm{mg}$ orally in addition to diet, exercise, and Metformin treatment. Since the patient had early onset severe obesity and hyperphagia, a gene panel targeted for genetic obesity was done. The patient was found to be heterozygous for the c.206T> G (p.I69R) (NM_005912.3) variant in the MC4R gene, which was previously described in the literature $(10,11)$. Since this variant was not detected in the parents, it was considered as de novo. When the patient was 17,9 years old her BMI was $52.87 \mathrm{~kg} / \mathrm{m} 2(4.89 \mathrm{SD})$, and upon obtaining the consent of the family, GLP1 RA Liraglutide treatment was initiated (8). In the first week of the treatment, a dose of $0.6 \mathrm{mg} / \mathrm{day}$ was administered subcutaneously, the dose was increased by $0.6 \mathrm{mg}$ once a week, and increased to the full dose $(3 \mathrm{mg} /$ day) in the fifth week. Her appetite reduced with treatment. Weight loss achieved after five weeks of treatment was $4.8 \%$. However, nausea, bloating, belching, intermittent abdominal pain, and gas-related pain became more pronounced with the increase to the full dose. Since gastrointestinal side effects associated with liraglutide therapy have been described $(8,9)$, the dose was reduced to $1.8 \mathrm{mg} /$ day, which the patient could tolerate. During the treatment process, the menstrual cycle delayed once. When the dose of Liraglutide was increased to $2.4 \mathrm{mg}$ /day due to the slowing down of the weight reduction rate, the complaints became apparent again and the dose was reduced again to $1.8 \mathrm{mg} / \mathrm{day}$. At the end of 32 weeks of regular use of the drug, a $19.2 \%$ reduction was achieved in her BW and BMI (Table 2). Since gastrointestinal complaints started with the initiation of the drug and became more pronounced with increasing the dose, and were relieved with dose reduction, it was strongly thought that they were related to drug side effects. The patient, who could not tolerate the gastrointestinal side effects, was observed to gain weight when she stopped taking the drug for two weeks. After starting the drug at a dose of $1.8 \mathrm{mg} /$ day, the weight gain stopped, but the patient decided to discontinue the drug and did not come to the follow up visits after 43 weeks. When the patient was reached by phone, it was learned that she returned to her pre-treatment weight $(145 \mathrm{~kg})$ a few months after she discontinued the drug.

Material-Method: DNA obtained from the patient's peripheral blood sample for genetic analysis was subjected to fragmentation, barcoding, library creation, target enrichment and amplification, and loaded into the next generation sequencing (NGS) device according to the protocol suggested by the manufacturer (MiSeq, Illumina, San Diego, CA). Custom panel containing 41 obesity-related genes previously prepared for sequencing (DYRK1B, LEP, LEPR, MC4R, NROB2, POMC, UCP3, ADRB2, ADRB3, AGRP, MC3R, NTRK2, PCSK1, SIM1, CARTPT, ENPP1, PPARB, PPARGC SDC3, UCP1, ADIPOQ, NAMPT, CFD, RETN, PPARGC1A, CCK, NPY, SLC2A4, ADD1, SREBF1, PTPN1, IRS-1, GHRL, BDNF, NEGR1, SH2B1, GIPR, TMEM18, FTO, SLC22) were used. Bioinformatics analyzes were performed using Qiagen Bioinformatics solutions (Quiagen, Hilden, Germany) software (QCI Analyze Universal 1.5.0 and Qiagen Clinical Insight Interpret) (4). The c.206T $>$ G, p.I69R variant in MC4R gene detected by NGS system was also analyzed and confirmed by Sanger sequencing. The amplicon was analyzed by direct sequencing with ABI 3500 (Life Technologies, Waltham, Massachusetts, USA). Analysis of sequence result was performed by Variant Surveyor Programme (SoftGenetics, USA). DISCUSSION

In this study, an adolescent obese girl with heterozygous variant in $M C 4 R$ gene was presented. She achieved weight loss with Liraglutide treatment, but could not maintain it due to gastrointestinal side effects and regained weight after discontinuing the drug. Melanocortin 4 receptor defect is characterized by early onset severe obesity, hyperphagia (more prominent especially in younger ages), increased linear growth, and insulin resistance (1). Our patient had excessive appetite and hyperphagia since infancy, and her obesity was progressing. Considering that obesity may have a genetic cause, gene panel testing was applied and heterozygous sporadic variant c.206T> G, p.I69R was detected in the MC4R gene This variant was previously reported in two morbidly obese children of Iraqi origin $(\mathbf{1 1 , 1 2})$. In accordance with the literature, the pubertal development of our case was normal and menarche age was 13.5 years. In addition to clinical and laboratory findings of insulin resistance, our patient also had cyclic neutropenia and recurrent urinary tract infection. It was thought that these pathologies, which were not described in previous reports could be incidental.

A standard obesity management method has not been defined in obese patients with $M C 4 R$ variants. In some of the studies investigating the effect of lifestyle change on weight loss in these patients, it was reported that patients with variants achieved 
weight loss similar to the control group, but it was observed that this could not be sustained in the long term $(6,13)$. Trier et al. reported that BMI SDS could be reduced in the control group after an average of 1 year of lifestyle change applications, but not in cases with $M C 4 R$ variants (7). Initially, lifestyle changes and oral metformin were recommended to our patient for obesity management. However, she could not limit food intake, continued to binge, and BMI, BMI SDS increased at each control. The addition of Orlistat, which is FDA approved in the treatment of obesity in children, was not effective either. In the literature, it has been reported that patients with heterozygous variants in the MC4R gene experienced a similar weight loss $(6 \%)$ compared to the control group after 16 weeks of treatment with GLP-1A Liraglutide (3 mg/d, subcutaneous) (8). There were no studies reporting long term data and evaluation after the discontinuation of the treatment. Bariatric surgery (especially with gastric bypass) has been reported to have similar results of weight loss for 1-3 years, in patients with MC4R defect compared to control obese patients. In some studies it has been shown that the long-term effects continued for 5-7 years and in others it was reported that the patients regained weight at the end of 5 years; while some studies have not revealed the pathogenicity of the variants clearly (10).

Liraglutide was approved by FDA, in 2014, for the treatment of obesity in adults. Later, in April 2020, FDA approved the use of the drug in adolescents (age $\geq 12$ years, BMI $\geq 30 \mathrm{~kg} / \mathrm{m} 2$, BW $>60 \mathrm{~kg}$ ). In our patient, GLP-1 RA Liraglutide treatment was started first on 20 June 2019, only 1-2 months before she was 18 years of age. In our patient, after 32 weeks of treatment with Liraglutide, $19.2 \%$ reduction was achieved in BW and BMI. However, the treatment could not be continued due to the gastrointestinal complaints, especially at doses above $1.8 \mathrm{mg} /$ day. It was learned that the patient returned to her initial weight within months after stopping the treatment. Gastrointestinal complaints were the most common side effects reported during Liraglutide therapy. In clinical studies of adult obese patients, it was reported that these side effects were usually well tolerated but also they led to discontinuation of treatment at a rate of $1.4-2.9 \%(9)$.

Since appetite control is poor due to genetic pathology in this group of patients, it seems that it is more difficult to maintain long-term effectiveness of the treatment. Therefore, in order to increase success in obesity management and to maintain it for a longer period, the side effects of existing treatment options should be decreased or surgical and medical reatments should be combined or new treatment options should be investigated.

\section{CONCLUSION}

Monogenic obesity should be considered in patients with early onset obesity and in whom appetite control cannot be achieved. In our case carrying $M C 4 R$ variant, Liraglutide treatment provided a decrease in appetite and $19.2 \%$ reduction in BW and BMI in 32 weeks. However, the treatment could not be continued due to side effects and she rapidly returned to previous weight after the discontinuation of the drug. In such cases, there is a need for effective treatment options with tolerable side effects in the long term.

\section{REFERENCES}

1) Farooqi IS, Keogh JM, Yeo GS, Lank EJ, Cheetham T, O Rahiliy S. Clinical spectrum of obesity and variants in the melanocortin 4 receptor gene. N Engl J Med. 2003 Mar 20;348(12):1085-1095. doi: 10.1056/NEJMoa022050. PMID: 12646665.

2) https://www.omim.org/entry/155541

3) Collet TH, Dubern B, Mokrosinski J, Connors H, Keogh JM, Mendes de Oliveira E, Henning E, Poitou-Bernert C, Oppert JM, Tounian P, Marchelli F, Alili R, Le Beyec J, Pépin D, Lacorte JM, Gottesdiener A, Bounds R, Sharma S, Folster C, Henderson B, O'Rahilly S, Stoner E, Gottesdiener K, Panaro BL, Cone RD, Clément K, Farooqi IS, Van der Ploeg LHT. Evaluation of a melanocortin-4 receptor (MC4R) agonist (Setmelanotide) in MC4R deficiency. Mol Metab. 2017 Oct;6(10):1321-1329. doi: 10.1016/j.molmet.2017.06.015.

4) Akıncı A, Türkkahraman D, Tekedereli İ, Özer L, Evren B, Şahin İ, Kalkan T, Çürek Y, Çamtosun E, Döğer E, Bideci A, Güven A, Eren E, Sangün Ö, Çayır A, Bilir P, Törel Ergür A, Ercan O. Novel Variants in Obesity-related Genes in Turkish Children with Non-syndromic Early Onset Severe Obesity: A Multicentre Study. J Clin Res Pediatr Endocrinol. 2019 Nov 22;11(4):341-349. doi: 10.4274/jcrpe.galenos.2019.2019.0021.

5) Aykut A, Özen S, Gökşen D, Ata A, Onay H, Atik T, Darcan Ş, Özkinay F. Melanocortin 4 receptor (MC4R) gene variants in children and adolescents having familial early-onset obesity: genetic and clinical characteristics. Eur J Pediatr. 2020 Sep;179(9):1445-1452. doi: 10.1007/s00431-020-03630-7.

6) Reinehr T, Hebebrand J, Friedel S, Toschke AM, Brumm H, Biebermann H, Hinney A. Lifestyle intervention in obese children with variations in the melanocortin 4 receptor gene. Obesity (Silver Spring). 2009 Feb;17(2):382-389. doi: 10.1038/oby 2008.422. Epub 2008 Nov 6. PMID: 18997677.

7) Trier C, Hollensted M, Schnurr TM, Lund MAV, Nielsen TRH, Rui G, Andersson EA, Svendstrup M, Bille DS, Gjesing AP, Fonvig CE, Frithioff-Bøjsøe C, Balslev-Harder M, Quan S, Gamborg M, Pedersen O, Ängquist L, Holm JC, Hansen T. Obesity treatment effect in Danish children and adolescents carrying Melanocortin-4 Receptor variants. Int J Obes (Lond). 2021 Jan;45(1):66-76. doi: 10.1038/s41366-020-00673-6.

8) Iepsen EW, Zhang J, Thomsen HS, Hansen EL, Hollensted M, Madsbad S, Hansen T, Holst JJ, Holm JC, Torekov SS. Patients with Obesity Caused by Melanocortin-4 Receptor Variants Can Be Treated with a Glucagon-like Peptide-1 Receptor Agonist. Cell Metab. 2018 Jul 3;28(1):23-32.e3. doi: 10.1016/j.cmet.2018.05.008.

9) Scott LJ. Liraglutide: a review of its use in the management of obesity. Drugs. 2015 May;75(8):899-910. doi: 10,1007/s40265-015-0408-8.

10) Vos N, Oussaada SM, Cooiman MI, Kleinendorst L, Ter Horst KW, Hazebroek EJ, Romijn JA, Serlie MJ,

Mannens MMAM, van Haelst MM. Bariatric Surgery for Monogenic Non-syndromic and Syndromic Obesity Disorders. Curr Diab Rep. 2020 Jul 30;20(9):44. doi: 10.1007/s11892-020-01327-7.

11) Wangensteen T, Kolsgaard ML, Mattingsdal M, Joner G, Tonstad S, Undlien D, Retterstol L. Variants in the melanocortin 4 receptor (MC4R) gene in obese patients in Norway. Exp Clin Endocrinol Diabetes. 2009 Jun;117(6):266-273. doi: $10.1055 / \mathrm{s}-0028-1102942$.

12) Birla S, Khandelwal D, Sharma A, Khadgawat R. MC4R Variant in Early-onset Severe Childhood ObesityGenotype-phenotype Correlation, US Endocrinology, 2017;13(02):69 DOI: 10.17925/USE.2017.13.02.69 


\begin{tabular}{|c|c|c|}
\hline Test & Results & Reference range \\
\hline White blood count $\left(10^{3} / \mathrm{ml}\right)$ & 2.5 & $4.3-10.3$ \\
\hline Hemoglobin g/dL & 12.6 & $13.6-17.2$ \\
\hline Mean corpuscular volume (fL) & 80.7 & $80.7-95.5$ \\
\hline Platelets $\left(10^{3} / \mathrm{ml}\right)$ & 242.000 & $150-400$ \\
\hline Alanin aminotransferase (IU/L) & 15 & $0-55$ \\
\hline Aspartate aminotransferase (IU/L) & 19 & $5-34$ \\
\hline Uric acid (mg/dL) & 5.4 & $2-5.5$ \\
\hline Total cholesterol $(\mathrm{mg} / \mathrm{dL})$ & 151 & $<170$ \\
\hline Low density lipoprotein (mg/dL) & 98 & $<130$ \\
\hline High density lipoprotein $(\mathrm{mg} / \mathrm{dL})$ & 44 & $40-60$ \\
\hline Triglyceride $(\mathrm{mg} / \mathrm{dL})$ & 45 & $<150$ \\
\hline Free Thyroxin (T4) (ng/dL) & 0.89 & $0.65-2.3$ \\
\hline Thyroid stimulant hormone $(\mu \mathrm{IU} / \mathrm{mL})$ & 3.5 & $0.33-6.0$ \\
\hline Cortisol $\mu \mathrm{g} / \mathrm{dL}(\mathrm{nmol} / \mathrm{L})$ & $9.67(266.8)$ & $5-23(138-635)$ \\
\hline ACTH $\mathrm{pg} / \mathrm{mL}(\mathrm{pmol} / \mathrm{L})$ & $23.6(5.20)$ & $7.2-63.3(1.6-13.9)$ \\
\hline $\begin{array}{l}\text { Cortisol after } 1 \mathrm{mg} \text { dexamethasone } \mu \mathrm{g} / \mathrm{dL} \\
(\mathrm{nmol} / \mathrm{L})\end{array}$ & $1.0(27.6)$ & $<1.8(49.7)$ \\
\hline Luteinising hormone (IU/L) & 0.77 & $0.1-12$ Tanner 3 \\
\hline Follicle stimulating hormone (IU/L) & 5.7 & 1.5-12.8 Tanner 3 \\
\hline Estradiol $(\mathrm{pg} / \mathrm{mL})$ & 80.2 & Tanner 3 \\
\hline Fasting glucose $\mathrm{mg} / \mathrm{dl}(\mathrm{mmol} / \mathrm{L})$ & $97(5.4)$ & $60-100(3.3-5.6)$ \\
\hline Fasting Insulin $\mu \mathrm{IU} / \mathrm{mL}(\mathrm{pmol} / \mathrm{L})$ & $50.8(352.8)$ & $6-27(41.7-187.5)$ \\
\hline Glucohemoglobin (\%) & 6 & $4-6$ \\
\hline $\begin{array}{l}\text { Oral glucose tolerans test } \\
120^{\prime} \text {, glucose } \mathrm{mg} / \mathrm{dl}(\mathrm{mmol} / \mathrm{L}) \\
120, \text { insulin } \mathrm{mg} / \mathrm{dl}(\mathrm{mmol} / \mathrm{L})\end{array}$ & $\begin{array}{l}112(6.2) \\
41.5(288.2)\end{array}$ & $\begin{array}{l}<140(<7.8) \\
<75(<520.8)\end{array}$ \\
\hline
\end{tabular}

Table 1: Results of laboratory analysis of the patient on first admissidn

Table 2: Changes in body weight and body mass index during liraglutide treatment in the follow up period

\begin{tabular}{|c|c|c|c|c|c|}
\hline Week & $\begin{array}{l}\text { Dosage } \\
\text { mg/day s.c }\end{array}$ & $\begin{array}{l}\text { Weight } \\
\text { kg }\end{array}$ & $\begin{array}{l}\text { Loss of Weight } \\
\mathbf{k g}(\%)\end{array}$ & $\begin{array}{l}\text { Body mass index (BMI) } \\
\mathrm{kg} / \mathrm{m} 2\end{array}$ & $\begin{array}{l}\text { Loss of BMI } \\
\mathrm{kg} / \mathrm{m} 2(\%)\end{array}$ \\
\hline 0 & 0.6 & $14 \overline{44.8}$ & - & 52.87 & - \\
\hline 5 & $3 *$ & $13 \overline{7.9}$ & $6.9(4.8)$ & 50.32 & $2.55(4.8)$ \\
\hline 8 & 1.8 & 134 & $10.8(7.5)$ & 48.90 & $3.97(7.5)$ \\
\hline 19 & 2.4 & 130.8 & $14.0(9.7)$ & 47.75 & $5.12(9.7)$ \\
\hline 26 & $2 . \overline{4^{*}}$ & 124 & $20.8(14.4)$ & 45.27 & $7.6(14.4)$ \\
\hline 32 & $18 *$ & 117 & $27.8(19.2)$ & 42.72 & $10.15(19.2)$ \\
\hline 36 & $\begin{array}{l}\text { After two weeks } \\
\text { of treatment } \\
\text { cessation }\end{array}$ & 124 & $20.8(14.4)$ & 45.27 & $7.6(14.4)$ \\
\hline $38-$ & 1.8 & 124 & $20.8(14.4)$ & 45.27 & $7.6(14.4)$ \\
\hline 43 & 1.8 & 126 & $18.8(13.0)$ & 46.00 & $6.87(13.0)$ \\
\hline 56 & $\begin{array}{l}\text { After } 13 \text { weeks of } \\
\text { treatment } \\
\text { cessation }\end{array}$ & $145 * *$ & & & \\
\hline
\end{tabular}

*Significant gastrointestinal side effects. s.c: subcutaneus**Weight measurement at home was learned over the phone. 